\title{
Associating Gait Phase and Physical Fitness with Global Cognitive Function in the Aged
}

\author{
Byungjoo Noh ${ }^{1}\left(\mathbb{D}\right.$, Changhong Youm ${ }^{1,2, *} \mathbb{C}$, Myeounggon Lee ${ }^{2}\left(\mathbb{D}\right.$ and Hwayoung Park ${ }^{2}(\mathbb{D}$ \\ 1 Department of Health Care and Science, College of Health Sciences, Dong-A University, Saha-gu, \\ Busan 49315, Korea; bnoh@dau.ac.kr \\ 2 Biomechanics Laboratory, College of Health Sciences, Dong-A University, Saha-gu, Busan 49315, Korea; \\ freestyle710@naver.com (M.L.); app00113@dau.ac.kr (H.P.) \\ * Correspondence: chyoum@dau.ac.kr; Tel.: +82-51-200-7830; Fax: +82-51-200-7505
}

Received: 25 May 2020; Accepted: 1 July 2020; Published: 3 July 2020

\begin{abstract}
This study aimed to identify classifier variables by considering both gait and physical fitness for identifying adults aged over 75 years and global cognitive function declines in older adults. The participants included 735 adults aged $65-89$ years who were asked to walk at three different speeds (slower, preferred, and faster) while wearing inertial measurement units embedded in shoe-type data loggers and to perform nine physical fitness tests. The variability in the stance phase as well as the strength, balance, and functional endurance showed a strong dependence on the age being over 75 years. The cognitive function was evaluated by the Mini-Mental State Examination; a longer stance phase at a slower walking speed and decreased grip strength and five times sit-to-stand were associated with cognitive function. These findings may be useful for determining the decline in physical performance of older adults. A longer stance phase and decreased grip strength and five times sit-to-stand may be factors that help distinguish declines in cognitive function from normal age-related declines.
\end{abstract}

Keywords: aging; dementia; cognitive decline; physical activity; inertial measurement unit

\section{Introduction}

Dementia is a serious health problem that can impact the physical health and quality of life of older adults [1]. The decline in cognitive function with age, which can lead to mild cognitive impairment and dementia, has been associated with functional limitations and disability [2]. This may be because motor performance is longitudinally associated with cognitive impairment [3] and dementia $[4,5]$. Furthermore, impairment of the motor system such as gait abnormality and a low level of physical fitness precede the onset of cognitive decline with age [3-5] or during the early stages of dementia [6]. Gait performance and cognitive function have shown distinct patterns of association, such as executive functions with gait variability $[7,8]$ and memory with the phase domain [8]. Moreover, slow walking is a significant predictor of cognitive decline or the risk of dementia $[9,10]$. Our previous study showed that decreased global cognitive function in older women can be associated with gait abnormalities such as increased gait variability and the phase domain at different gait speeds [11]. Gait abnormality may not only increase the risk of dementia in older adults but also indicate a low level of physical fitness in domains [5] such as mobility [12], balance [13], strength [14], and aerobic fitness [15]. It is not difficult to find a relationship between physical fitness, including mobility, and cognitive function in older adults [16].

A limited study investigated the phase domain for assessing cognitive function declines; lower global cognitive function showed the strongest relationship with a longer stance phase in older adults aged over 75 years [11,17], which could lead to falling [18]. This effect may be aggravated in older 
adults aged over 75 years because physiological changes may occur above this age threshold [19]. In addition, some studies performed multiple physical performance tests for identifying physical functions associated with cognitive functions [20-22]. Studies of physical performance characteristics for assessing declines in cognitive function remain necessary for identifying at different approaches with several gait variables (not only gait speed) with numerous consecutive steps and physical fitness variables. Further, the relations of both gait and physical fitness domains with declines in cognitive function should be investigated. In this light, the present study aims to identify the following:

- Classifier variables for identifying declines in physical function in adults aged over 75 years by assessing gait and physical fitness variables;

- Domain parameters of the gait at three different walking speeds and physical fitness that are strongly associated with lower global cognitive function in older adults.

\section{Materials and Methods}

\subsection{Participants}

This study was conducted as part of a community-wide survey in Busan Metropolitan City in 2018-2019. We recruited 844 participants aged 65-89 years through advertisements placed in the local community (a power $>80 \%$ ). The inclusion criteria for participants were as follows: (a) age of 65-89 years, (b) no musculoskeletal injuries, and (c) no history of neurological problems within the last 6 months. In total, 735 participants took part in the over-ground walking and physical fitness tests (Figure 1). All participants provided written informed consent. This study was approved by the Institutional Review Board of Dong-A University (IRB number: 2-1040709AB-N-01-201808-HR-023-02).

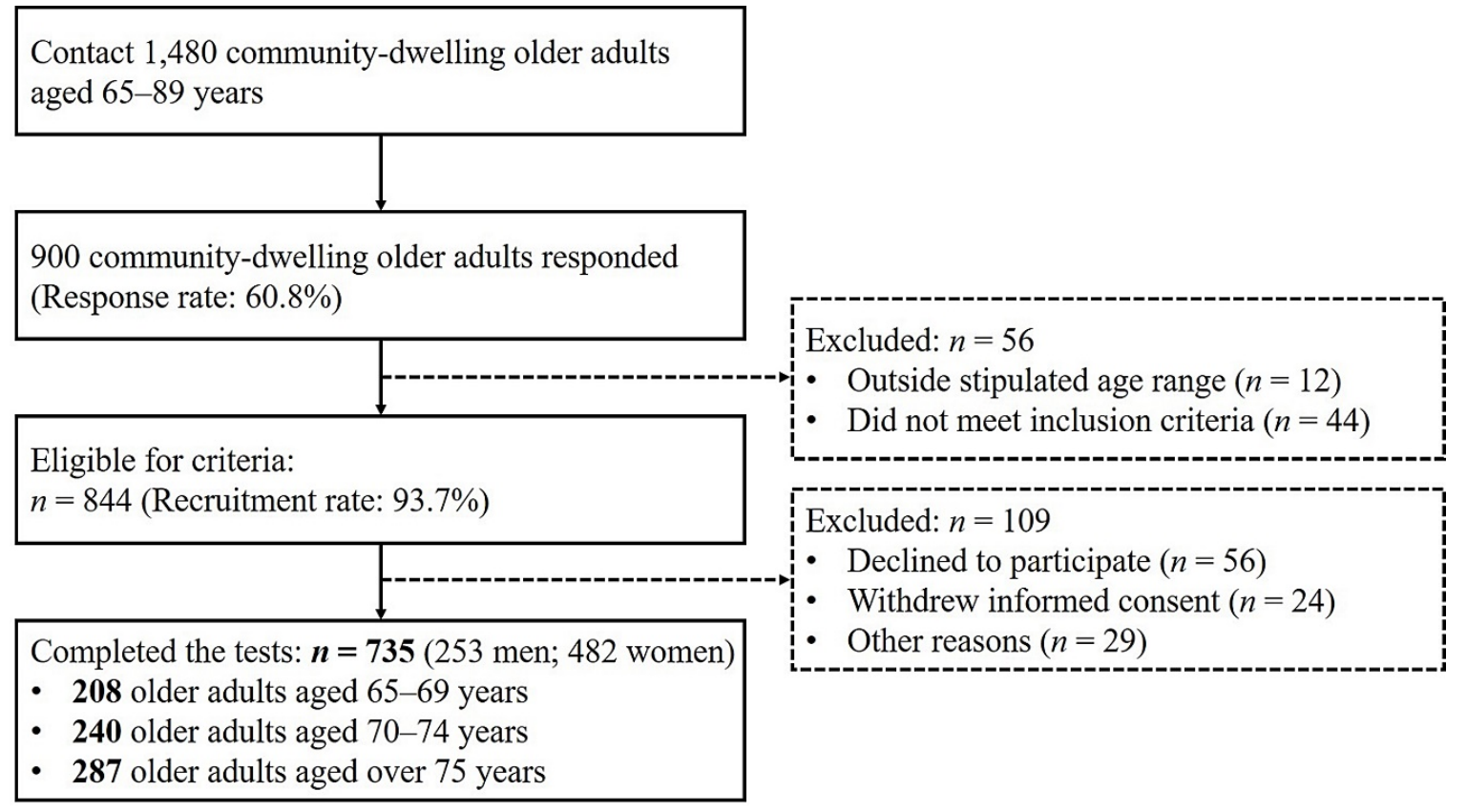

Figure 1. Flow diagram for participant recruitment.

\subsection{Instrumentation}

Data were collected with a gait analysis system (DynaStab ${ }^{\mathrm{TM}}$, JEIOS, Busan, South Korea) comprising shoe-type data loggers (Smart Balance SB- $1^{\circledR}$, JEIOS, Busan, South Korea). The data logger was embedded with Bluetooth inertial measurement unit (IMU) sensors (IMU-3000 ${ }^{\mathrm{TM}}$, InvenSense, San Jose, CA, USA) on both side outsoles. Tri-axial acceleration (up to $\pm 6 g$ ) and tri-axial angular 
velocities (up to $\pm 500^{\circ} \mathrm{s}^{-1}$ ) along three orthogonal axes were sampled at a sampling frequency of 100 $\mathrm{Hz}$ using a data acquisition system (Smart Balance version 1.5, JEIOS, Busan, South Korea) [23,24]. The IMU sensors were constructed using a local coordinate system with anterior/posterior, medial/lateral, and vertical coordinates [23].

\subsection{Test Procedures}

Prior to the over-ground walking test and physical fitness test, biometric data (InBody 270, Biospace, Seoul, South Korea) of all participants were recorded. Participants were asked to answer the habitual physical activity (PA) questionnaire. Habitual physical activity levels were evaluated with the use of the international physical activity questionnaire-short form, which pertained to the self-reported physical activity of the participants. The total metabolic equivalents (MET-min/week) were calculated based on this questionnaire [25]. Participants were verbally instructed with a visual demonstration to perform over-ground walking for $10 \mathrm{~min}$ as a familiarization.

\subsubsection{Global Cognitive Function}

The Mini-Mental State Examination (MMSE) was used to assess global cognitive function; this is a widely used test of global cognitive function and screening tool for dementia [26]. Participants were answered a 30-point questionnaire that includes tests pertaining to orientation, attention, memory, language, and visual-spatial skills. Participants were categorized as having normal cognitive function if they had an MMSE score of 24 or greater and having abnormal cognitive function if they scored below 24. For evaluations, the MMSE score was normalized by the Z-score ((value-mean)/standard deviation) because it is not supposed to be used as a continuous variable.

\subsubsection{Physical Fitness Test}

We assessed four domains of physical fitness: strength (upper/lower body), flexibility (upper/lower body), balance (static/dynamic), and functional (or cardiorespiratory) endurance. All participants completed nine physical fitness tests in the following order (see Table S1):

1. Grip strength (dominant hand) was measured with an isometric digital handgrip dynamometer (TKK 5401 Grip-D, Takei Scientific Instruments, Tokyo, Japan) to assess the upper body strength;

2. Bicep curls were performed with a dumbbell ( $3 \mathrm{~kg}$ for men, $2 \mathrm{~kg}$ for women) to assess the upper body strength;

3. Sit-to-stand was performed five times to assess the lower body strength;

4. Standing time (ST) from a long sitting position (LSP) was measured to assess the lower body strength;

5. Back scratching to assess the upper body flexibility;

6. Chair sit and reach to assess the lower body flexibility;

7. Single-leg balance (dominant leg) to assess the static balance;

8. A $3 \mathrm{~m}$ timed-up-and-go test to assess the dynamic balance; and

9. A 6 min walk test to assess the functional (or cardiorespiratory) endurance.

The mean scores were calculated for two attempts of each physical fitness test. For further analysis, the scores of each physical fitness test were normalized into Z-scores of all variables.

\subsubsection{Over-Ground Walking Test at Different Speeds}

The over-ground walking test along a straight $20 \mathrm{~m}$ walkway at $80 \%$ of usual (slower), usual walking (preferred), and $120 \%$ of usual (faster) speeds were performed three times. The preferred speed is normally used in daily activities without any support during over-ground walking. The $20 \%$ slower and faster walking speed was calculated relative to the preferred speed [27], which were quantified using a metronome (beats/min). Participants were asked to perform the over-ground walking test as close as 
possible to the target slower and faster walking speed paced by a metronome [11]. The participants completed the over-ground walking test wearing the shoe-type data loggers with multiple shoe sizes to fit the tested individuals.

\subsection{Data Analysis}

The over-ground walking data (see Supplementary Materials Table S2: Raw data) from a gait analysis system were passed through a second-order Butterworth low-pass filter with a cutoff frequency of $10 \mathrm{~Hz}[23,24]$. We excluded the two initial steps (acceleration) and two final steps at the end of the test (deceleration) for analyzing the steady-state condition. Heel strikes and toe-offs were identified that occurred when the linear acceleration along the antero-posterior axis and the vertical axis reached its maximum value during a gait cycle, respectively $[23,24]$. The stance phase as a phase domain and the coefficient of variance $(\mathrm{CV}$, (standard deviation/mean) $\times 100)$ values for the stance phase as a gait variability were calculated. The gait variable was normalized to Z-scores for all variables.

\section{Covariates}

The covariates included in the analysis were age, sex, body mass index, level of education, and PA level. The level of education was defined as a categorical variable (elementary school education or less, middle school education, high school education, college degree, or higher).

\subsection{Statistical Analyses}

The Shapiro-Wilk test was used to examine whether a variable is normally distributed. An independent sample t-test was performed to compare differences in demographics, MMSE score, gait parameters at the three different walking speeds, and physical fitness parameters. Binary logistic regression was conducted to determine classifiers for identifying the declined gait abilities and physical fitness of participants aged over 75 years at each walking speed and the physical fitness domain, which contained all confounders. The logistic regression model results were reported in terms of the odds ratio (OR) and 95\% confidence interval (CI). Subsequently, stepwise multivariable linear regression analysis was performed to identify the independent variables (each gait speed and physical fitness domains) and explain the significance of the dependent variables (MMSE scores). All models used the MMSE scores, gait variables (stance phase and CV of stance phase at three different speeds), and physical fitness variables (grip strength, biceps curls, five times sit-to-stand, ST from an LSP, back scratching, chair sit and reach, single-leg balance, $3 \mathrm{~m}$ timed up-and-go, and $6 \mathrm{~min}$ walk). The analyses were conducted by using SPSS for Windows (version 25.0, IBM Corp., Armonk, NY, USA), and the level of significance was $p<0.05$.

\section{Results}

\subsection{Demographics and Characteristics of Physical Performance}

Table 1 presents the demographic, gait, and physical fitness characteristics of the 735 participants included in the study. The participants had an average age of $73.1 \pm 5.1$ years (range: 65-89 years). The men had greater physical activity $(p<0.001)$, more years of education $(p<0.001)$, and higher MMSE scores $(p=0.023)$ than the women. With respect to the gait variables, the men showed a lower stance phase than the women at all three walking speeds $(p<0.001)$. With respect to the physical fitness variables, the men performed better than the women at the grip strength, bicep curls, five-time sit-to-stand, ST from an LSP, 3 m timed-up-and-go, 6-min walk, lower back scratching, and chair sit and reach (all $p<0.001)$. 
Table 1. Demographic, gait, and physical fitness characteristics of participants.

\begin{tabular}{|c|c|c|c|c|}
\hline Variables & All Participants $(n=735)$ & Older Men $(n=253)$ & Older Women $(n=482)$ & $p$-Value \\
\hline Age (years) & $73.1 \pm 5.1$ & $74.2 \pm 5.2$ & $72.6 \pm 5.0$ & $<0.001$ \\
\hline Height $(\mathrm{cm})$ & $157.3 \pm 8.1$ & $165.6 \pm 5.9$ & $152.9 \pm 5.2$ & $<0.001$ \\
\hline Body weight $(\mathrm{kg})$ & $61.1 \pm 8.7$ & $66.7 \pm 7.6$ & $58.3 \pm 7.9$ & $<0.001$ \\
\hline Body mass index $\left(\mathrm{kg} / \mathrm{m}^{2}\right)$ & $24.7 \pm 2.9$ & $24.3 \pm 2.4$ & $24.9 \pm 3.1$ & 0.003 \\
\hline Total PA (MET-min/week) & $1873.7 \pm 1792.7$ & $2225.2 \pm 1771.7$ & $1689.2 \pm 1777.8$ & $<0.001$ \\
\hline Education (years) & $9.1 \pm 3.9$ & $10.5 \pm 4.0$ & $8.4 \pm 3.7$ & $<0.001$ \\
\hline 0 year & $36(4.9 \%)$ & $7(2.8 \%)$ & $29(6.0 \%)$ & \\
\hline $1-6$ years & $249(33.9 \%)$ & $57(22.5 \%)$ & $192(39.8 \%)$ & \\
\hline $7-12$ years & $373(50.7 \%)$ & $142(56.1 \%)$ & $231(47.9 \%)$ & \\
\hline$>13$ years & $77(10.5 \%)$ & $47(18.5 \%)$ & $30(6.2 \%)$ & \\
\hline MMSE score & $26.4 \pm 2.9$ & $26.8 \pm 2.7$ & $26.3 \pm 3.0$ & 0.023 \\
\hline$<24$ & $100(13.6 \%)$ & $27(10.7 \%)$ & $73(15.1 \%)$ & \\
\hline \multicolumn{5}{|l|}{ Slower speed } \\
\hline Stance phase (\%) & $59.2 \pm 1.6$ & $58.9 \pm 1.6$ & $59.4 \pm 1.6$ & $<0.001$ \\
\hline CV of stance phase (\%) & $4.5 \pm 2.2$ & $4.4 \pm 2.2$ & $4.6 \pm 2.2$ & 0.279 \\
\hline \multicolumn{5}{|l|}{ Preferred speed } \\
\hline Stance phase (\%) & $57.5 \pm 1.7$ & $57.1 \pm 1.7$ & $57.7 \pm 1.7$ & $<0.001$ \\
\hline CV of stance phase (\%) & $3.0 \pm 1.7$ & $3.1 \pm 1.7$ & $2.9 \pm 1.7$ & 0.379 \\
\hline \multicolumn{5}{|l|}{ Faster speed } \\
\hline Stance phase (\%) & $55.7 \pm 1.8$ & $55.2 \pm 1.9$ & $55.9 \pm 1.8$ & $<0.001$ \\
\hline $\mathrm{CV}$ of stance phase (\%) & $2.4 \pm 1.3$ & $2.3 \pm 1.3$ & $2.4 \pm 1.3$ & 0.691 \\
\hline \multicolumn{5}{|l|}{ Physical fitness } \\
\hline Grip strength $(\mathrm{kg})$ & $25.9 \pm 7.4$ & $33.4 \pm 6.1$ & $22.0 \pm 4.3$ & $<0.001$ \\
\hline Biceps curl (no. of reps.) & $25.9 \pm 7.7$ & $28.5 \pm 8.2$ & $24.6 \pm 7.1$ & $<0.001$ \\
\hline Five times sit-to-stand (s) & $9.7 \pm 3.7$ & $9.1 \pm 3.2$ & $10.0 \pm 3.9$ & $<0.001$ \\
\hline ST from an LSP (s) & $3.6 \pm 2.1$ & $3.2 \pm 1.8$ & $3.8 \pm 2.2$ & $<0.001$ \\
\hline Back scratch $(\mathrm{cm})$ & $-12.7 \pm 13.5$ & $-20.1 \pm 14.0$ & $-8.8 \pm 11.5$ & $<0.001$ \\
\hline Chair sit and reach $(\mathrm{cm})$ & $18.4 \pm 10.5$ & $11.3 \pm 10.8$ & $22.1 \pm 8.2$ & $<0.001$ \\
\hline Single-leg balance (s) & $18.2 \pm 20.3$ & $17.9 \pm 19.1$ & $18.4 \pm 20.9$ & 0.735 \\
\hline $3 \mathrm{~m}$ timed-up-and-go (s) & $7.8 \pm 2.3$ & $7.2 \pm 2.3$ & $8.1 \pm 2.2$ & $<0.001$ \\
\hline 6-min walk (m) & $463.6 \pm 105.6$ & $495.8 \pm 110.4$ & $446.7 \pm 99.0$ & $<0.001$ \\
\hline
\end{tabular}

Mean \pm SD: mean and standard deviation; PA: physical activity; METs: metabolic equivalents; MMSE: mini-mental state examination; CV: coefficient of variance; ST: standing time; LSP: long sitting position; boldface denotes a significant difference between older men and women; significant difference: $p<0.05$.

\subsection{Gait Classifiers with Three Different Speed and Physical Fitness Variables to Identify Participants Aged} Above 75 Years

Table 2 summarizes only the statistically significant results from the binary logistic regression for all participants. The binary logistic regression models for identifying participants over 75 years by gait and physical fitness variables showed that the ORs were significantly different for the MMSE score (OR: $0.605 ; p<0.001)$ and CV of the stance phase at the preferred speed (OR: $1.626 ; p=0.024)$ in the over-ground walking test. In addition, the ORs were significantly different for the grip strength (OR: 0.541; $p<0.001$ ), single-leg balance (OR: $0.491 ; p<0.001$ ), and 6-min walk (OR: $0.451 ; p<0.001$ ) in the physical fitness test.

Table 2. Summary of binary logistic regression model for identifying participants aged over 75 years.

\begin{tabular}{ccccc}
\hline Predictors & $\boldsymbol{\beta}$ (SE) & Odds Ratio & $\mathbf{9 5 \% ~ C I}$ & $p$-Value \\
\hline $\begin{array}{c}\text { MMSE score } \\
\text { Over-ground walking }\end{array}$ & $-0.503(0.092)$ & 0.605 & $0.505-0.724$ & $<0.001$ \\
CV of stance phase (preferred) & $0.486(0.216)$ & 1.626 & $1.065-2.483$ & 0.024 \\
$\begin{array}{c}\text { Physical fitness } \\
\text { Grip strength }\end{array}$ & $-0.614(0.162)$ & 0.541 & $0.394-0.744$ & $<0.001$ \\
Single-leg balance & $-0.712(0.138)$ & 0.491 & $0.375-0.642$ & $<0.001$ \\
6-min walk & $-0.797(0.173)$ & 0.451 & $0.321-0.633$ & $<0.001$ \\
\hline
\end{tabular}

Model adjusted for sex, body mass index, education level, and physical activity level. SE: standard error; CI: confidence interval; MMSE: mini-mental state examination; CV: coefficient of variance; significant difference: $p<0.05$. 


\subsection{Association of Gait with the MMSE Score}

Table 3 lists only the statistically significant results for the association of gait at three different speeds and physical fitness variables with the MMSE score of older adults. After adjustments to the confounders, the stance phase at the slower speed $(\beta=0.088, p=0.023)$, grip strength $(\beta=0.148$, $p<0.001)$, and five times sit-to-stand $(\beta=-0.111, p=0.003)$ showed a significant association with the MMSE score.

Table 3. Association of gait at three different speeds and physical fitness variables with global cognitive function in older adults.

\begin{tabular}{cccc}
\hline Variables & \multicolumn{3}{c}{ MMSE Score } \\
\cline { 2 - 4 } & $\boldsymbol{\beta}(\mathrm{SE})$ & $\boldsymbol{t}$ & $\boldsymbol{p}$-Value \\
\hline Overground walking & & $\boldsymbol{R}^{\mathbf{2}}=\mathbf{0 . 1 9 1}$ \\
Stance phase (slow) & $0.088(0.039)$ & 2.276 & 0.023 \\
Physical fitness & & $\boldsymbol{R}^{\mathbf{2}}=\mathbf{0 . 2 3 6}$ & \\
Grip strength & $0.148(0.036)$ & 4.076 & $<0.001$ \\
Five times sit-to-stand & $-0.111(0.037)$ & -3.025 & 0.003 \\
\hline
\end{tabular}

Model adjusted for age, sex, body mass index, education level, and physical activity level. MMSE: mini-mental state examination; SE: standard error; significant difference, $p<0.05$.

\section{Discussion}

This study demonstrated classifier variables for participants over 75 years and a sensitive assessment for identifying declines in global cognitive function in older adults. The key findings are as follows:

1. The gait and nine physical fitness variables indicated that the variability in the stance phase and the strength, balance, and functional endurance showed a strong dependence on the age being over 75 years.

2. The stance phase at the slower walking speed and grip strength and five times sit-to-stand were associated with the global cognitive function in older adults.

\subsection{Gait and Physical Fitness Domain Parameters Reflecting Age over 75 Years}

With respect to gait variables, higher gait variability; lower strength, static balance, and functional endurance; and lower cognitive function showed a strong dependence on the age being over 75 years. Our findings are consistent with those of previous studies reporting that the variability domain for women aged over 75 years [11] and physical fitness [28] are highly dependent on aging. This relationship may be related to increased stride-to-stride fluctuations during walking because of greater foot contact time on the ground from decreased cognitive function. This may lead to dynamic gait instability in individuals aged over 75 years, who have a lower static balance than individuals aged below 75 years. Furthermore, lower muscular strength may increase gait variability responses [29]. This is supported by the finding that decreased dynamic gait stability is associated with less steady force output during walking, which depends on a decline in motor control and the automatic stepping mechanism [30,31]. In addition, 78 years may be the threshold age for when physiological changes occur in the human plasma proteome [19]. Therefore, our results may identify parameters for motor changes at the threshold age of 75 years. Gait variability, muscular strength, balance, and functional endurance should be useful parameters for identifying changes in motor patterns of the aged. Physical performances are more vulnerable in women. For example, the $3 \mathrm{~m}$ timed-up-and-go test showed that the women had a longer stance phase and worse dynamic balance than the men. The female disadvantage has been well-established among older adults: women have a higher life expectancy but, ironically, perform worse [32,33] because of less physical activity and walking [34]. Further, morphological differences in sex, such as anatomy and physiology, affect the neuromuscular performance $[29,35,36]$. Women 
have smaller skeletal muscles and a lower percentage of type II muscle fibers [36,37] because of sex-related differences in human skeletal muscle gene expression and interactions with sex-specific hormones [38,39].

\subsection{Identifying Cognitive Function Decline According to Gait and Physical Fitness Variables}

Previous studies have presented similar findings: an association among a longer stance phase, lower strength (grip strength and five times sit-to-stand), and cognitive function decline in older adults $[8,11,14,17]$. In contrast, biceps curl and ST from an LSP did not show any significant association with cognitive function. Biceps curls involve repetitive arm movements with light loading (men: $3 \mathrm{~kg}$; women $2 \mathrm{~kg}$ ) that is close to the muscle endurance. A longer stance phase in aged individuals with cognitive function decline may contribute to a decreasing walking speed and manifest owing to inadequate propulsive force. The optimal propulsive force generation should be achieved during the stance phase [11]. This inadequate propulsive force generation may also be due to reduced muscular strength based on the results of the physical fitness test. Previous studies' results supported an association between lower upper- and lower-body muscular strength and lower cognitive function in older adults $[40,41]$. This may be linked to the decreased volumes of gray and white matter in multiple brain regions and white matter hyperintensities [42]. Furthermore, dynamic stability is affected by a longer stance phase during walking. This factor would also increase the risk of falling in aged individuals with cognitive function decline. Indeed, a longer stance phase during walking could be used to distinguish cognitive function decline from normal age-related decline.

Our over-ground walking test with modified gait speeds, especially the slower speed, may have served as a dual-task. The stance phase at the slower walking speed showed an association with the global cognitive function. Gait speed modification, which is the volitional control of movement, may be generated in response to supraspinal inputs but not owing to underlying locomotor patterns by a network of spinal interneurons (commonly referred to as the central pattern generator (CPG)) at the spinal cord level $[43,44]$. Furthermore, as they age, older adults become less peripherally aware during walking and less sensitive to peripheral reflexes with more reliance on central regulation [45]. Song and Geyer suggested that feedback integration may be functionally more important than the CPG to human locomotion [46]. Therefore, a walking test with speed modification could be a suitable method for assessing cognitive function decline in older adults. We suggest that cognitive function may be improved in older adults through approaches such as physical activities or modifying the walking speed based on auditory feedback, which can help evoke supraspinal inputs.

Previous studies have reported that slow walking speed is associated with cognitive function decline [47]. However, walking speed was not considered as a gait variable in the study, even though a reduced walking speed may be effective variable for predicting a decline in cognitive functions. Nevertheless, in the past decades, walking speed has been useful to assess the health status (e.g., frailty and dementia) in clinical utilities. However, in recent year, there has been a high demand for new approaches that use low-cost-IMU-sensors-embedded gait assessment system to assess health status [48]. Specifically, clinical and research settings can use this system to precisely assess the health status with several gait variables (e.g., phases, variability, and gait asymmetry). Therefore, we considered the over-ground walking test with consecutive steps to strengthen the reliability of the gait variables.

Our findings must be considered within the limitations of the study. First, the over-ground walking test was not directly conducted as a dual-task (i.e., combined motor and cognitive tasks) to measure the associations between motor and cognitive functions. Therefore, the stance phase at faster walking speed may not show a significant association with cognitive function. However, gait speed modification may obtain the effects of a dual-task because gait analysis under various walking speed conditions may be challenging for individuals with cognitive function decline [31]. Therefore, gait speed modification may help with determining cognitive function decline through motor functions. Second, our findings cannot exclude the possibility of sampling bias for sex (482 older 
women vs. 253 older men). Women yielded slower walking speeds with shorter step lengths and worse muscle strength than men; this pattern may affect the results observed in the physical performance, even though the models were adjusted for sex. Third, the over-ground walking test was conducted with an IMU-based gait analysis system. Even though this system has been validated for the motion capture of patients with Parkinson's disease, further validation should be performed in various environments and with subjects having various variables. Fourth, this study was based on cross-sectional rather than longitudinal data. Further studies should follow the same sample of older adults over time. Fifth, the ST from an LSP, which was included to reflect older adults' tendency to sit on the floor in Asian cultures, was not associated with cognitive function despite five times sit-to-stand was associated due to the violation of the multicollinearity. Thus, this issue should be considered when interpreting the results. Lastly, the MMSE was only used to assess the global cognitive function. Fundamentally, the MMSE was used as a screening test of global cognitive function or dementia; it could not measure certain cognitive functions although several studies have used it to assess global cognitive function $[11,17,49]$.

\section{Conclusions}

In the study, we found that the stance phase at three different walking speeds and physical fitness levels should be considered as classifier variables to identify gait and physical fitness declines in individuals aged 75 years or older. In addition, declined cognitive function was associated with a longer stance phase at a slower walking speed and decreased grip strength and five times sit-to-stand in older adults. Our results are useful for determining the decline in physical performance of older adults and may potentially be used in clinical environments to measure the effectiveness of interventions meant to prevent or delay cognitive impairment.

Supplementary Materials: The following are available online at http://www.mdpi.com/1660-4601/17/13/4786/s1, Table S1: Physical fitness test protocols, Table S2: Raw data.

Author Contributions: Conceptualization, B.N., C.Y., M.L., and H.P.; methodology, B.N., C.Y., M.L., and H.P.; validation, B.N., C.Y., M.L., and H.P.; formal analysis, B.N., C.Y., and M.L.; investigation, B.N., C.Y., and H.P.; resources, B.N., C.Y., and H.P.; data curation, B.N., C.Y., M.L., and H.P.; writing-original draft preparation, B.N., C.Y., and M.L.; writing-review and editing, B.N., C.Y., M.L., and H.P. All authors have read and agreed to the published version of the manuscript.

Funding: This research was funded by the Sports Promotion Fund of Seoul Olympic Sports Promotion Foundation from the Ministry of Culture, Sports and Tourism, grant number B0080605000494.

Acknowledgments: The authors thank the biomechanics laboratory staff at Dong-A University for their assistance with data collection.

Conflicts of Interest: The authors declare no conflict of interest.

\section{References}

1. Doi, T.; Shimada, H.; Makizako, H.; Tsutsumimoto, K.; Uemura, K.; Anan, Y.; Suzuki, T. Cognitive function and gait speed under normal and dual-task walking among older adults with mild cognitive impairment. BMC Neurol. 2014, 14, 67. [CrossRef]

2. Tait, J.L.; Duckham, R.L.; Milte, C.M.; Main, L.C.; Daly, R.M. Influence of sequential vs. simultaneous dual-task exercise training on cognitive function in older adults. Front. Aging Neurosci. 2017, 9, 368. [CrossRef] [PubMed]

3. Marquis, S.; Moore, M.M.; Howieson, D.B.; Sexton, G.; Payami, H.; Kaye, J.A.; Camicioli, R. Independent predictors of cognitive decline in healthy elderly persons. Arch. Neurol. 2002, 59, 601-606. [CrossRef] [PubMed]

4. Verghese, J.; Lipton, R.B.; Hall, C.B.; Kuslansky, G.; Katz, M.J.; Buschke, H. Abnormality of gait as a predictor of non-Alzheimer's dementia. N. Engl. J. Med. 2002, 347, 1761-1768. [CrossRef] [PubMed]

5. Wang, L.; Larson, E.B.; Bowen, J.D.; van Belle, G. Performance-based physical function and future dementia in older people. Arch. Intern. Med. 2006, 166, 1115-1120. [CrossRef] [PubMed] 
6. Albers, M.W.; Gilmore, G.C.; Kaye, J.; Murphy, C.; Wingfield, A.; Bennett, D.A.; Boxer, A.L.; Buchman, A.S.; Cruickshanks, K.J.; Devanand, D.P.; et al. At the interface of sensory and motor dysfunctions and Alzheimer's disease. Alzheimer's Dement. 2015, 11, 70-98. [CrossRef]

7. Hausdorff, J.M.; Yogev, G.; Springer, S.; Simon, E.S.; Giladi, N. Walking is more like catching than tapping: Gait in the elderly as a complex cognitive task. Exp. Brain Res. 2005, 164, 541-548. [CrossRef]

8. Verlinden, V.J.; Van der Geest, J.N.; Hofman, A.; Ikram, M.A. Cognition and gait show a distinct pattern of association in the general population. Alzheimer's Dement. 2014, 10, 328-335. [CrossRef]

9. Aggarwal, N.T.; Wilson, R.S.; Beck, T.L.; Bienias, J.L.; Bennett, D.A. Motor dysfunction in mild cognitive impairment and the risk of incident Alzheimer disease. Arch. Neurol. 2006, 63, 1763-1769. [CrossRef]

10. Mielke, M.M.; Roberts, R.O.; Savica, R.; Cha, R.; Drubach, D.I.; Christianson, T.; Pankratz, V.S.; Geda, Y.E.; Machulda, M.M.; Ivnik, R.J.; et al. Assessing the temporal relationship between cognition and gait: Slow gait predicts cognitive decline in the Mayo Clinic study of aging. J. Gerontol. A Biol. Sci. Med. Sci. 2013, 68, 929-937. [CrossRef]

11. Noh, B.; Youm, C.; Lee, M.; Park, H. Age-specific differences in gait domains and global cognitive function in older women: Gait characteristics based on gait speed modification. PeerJ 2020, 8, e8820. [CrossRef] [PubMed]

12. Huh, Y.; Yang, E.J.; Lee, S.A.; Lim, J.Y.; Kim, K.W.; Paik, N.J. Association between executive function and physical performance in older Korean adults: Findings from the Korean Longitudinal Study on Health and Aging (KLoSHA). Arch. Gerontol. Geriatr. 2011, 52, e156-e161. [CrossRef] [PubMed]

13. Sattler, C.; Erickson, K.I.; Toro, P.; Schröder, J. Physical fitness as a protective factor for cognitive impairment in a prospective population-based study in Germany. J. Alzheimer's Dis. 2011, 26, 709-718. [CrossRef] [PubMed]

14. Annweiler, C.; Schott, A.M.; Van Kan, G.A.; Rolland, Y.; Blain, H.; Fantino, B.; Herrmann, F.R.; Beauchet, O. The five-times-sit-to-stand test, a marker of global cognitive functioning among community-dwelling older women. J. Nutr. Health Aging 2011, 15, 271-276. [CrossRef] [PubMed]

15. Kramer, A.F.; Erickson, K.I.; Colcombe, S.J. Exercise, cognition, and the aging brain. J. Appl. Physiol. 2006, 101, 1237-1242. [CrossRef]

16. Voelcker-Rehage, C.; Godde, B.; Staudinger, U.M. Physical and motor fitness are both related to cognition in old age. Eur. J. Neurosci. 2010, 31, 167-176. [CrossRef]

17. Taniguchi, Y.; Watanabe, Y.; Osuka, Y.; Kitamura, A.; Seino, S.; Kim, H.; Kawai, H.; Sakurai, R.; Inagaki, H.; Awata, S.; et al. Characteristics for gait parameters of community-dwelling elderly Japanese with lower cognitive function. PLoS ONE 2019, 14, e0212646. [CrossRef]

18. Aboutorabi, A.; Arazpour, M.; Bahramizadeh, M.; Hutchins, S.W.; Fadayevatan, R. The effect of aging on gait parameters in able-bodied older subjects: A literature review. Aging Clin. Exp. Res. 2016, 28, $393-405$. [CrossRef]

19. Lehallier, B.; Gate, D.; Schaum, N.; Nanasi, T.; Lee, S.E.; Yousef, H.; Losada, P.M.; Berdnik, D.; Keller, A.; Verghese, J.; et al. Undulating changes in human plasma proteome profiles across the lifespan. Nat. Med. 2019, 25, 1843-1850. [CrossRef]

20. Atkinson, H.H.; Rapp, S.R.; Williamson, J.D.; Lovato, J.; Absher, J.R.; Gass, M.; Henderson, V.W.; Johnson, K.C.; Kostis, J.B.; Sink, K.M.; et al. The relationship between cognitive function and physical performance in older women: Results from the women's health initiative memory study. J. Gerontol. A Biol. Sci. Med. Sci. 2010, 65, 300-306. [CrossRef]

21. Veronese, N.; Stubbs, B.; Trevisan, C.; Bolzetta, F.; De Rui, M.; Solmi, M.; Sartori, L.; Musacchio, E.; Zambon, S.; Perissinotto, E.; et al. What physical performance measures predict incident cognitive decline among intact older adults? A 4.4 year follow up study. Exp. Gerontol. 2016, 81, 110-118. [CrossRef] [PubMed]

22. Abe, T.; Soma, Y.; Kitano, N.; Jindo, T.; Sato, A.; Tsunoda, K.; Tsuji, T.; Okura, T. Change in hand dexterity and habitual gait speed reflects cognitive decline over time in healthy older adults: A longitudinal study. J. Phys. Ther. Sci. 2017, 29, 1737-1741. [CrossRef] [PubMed]

23. Lee, M.; Youm, C.; Jeon, J.; Cheon, S.; Park, H. Validity of shoe-type inertial measurement units for Parkinson's disease patients during treadmill walking. J. Neuroeng. Rehabil. 2018, 15, 38. [CrossRef] [PubMed]

24. Kim, Y.K.; Joo, J.Y.; Jeong, S.H.; Jeon, J.H.; Jung, D.Y. Effects of walking speed and age on the directional stride regularity and gait variability in treadmill walking. J. Mech. Sci. Technol. 2016, 30, 2899-2906. [CrossRef] 
25. Oyeyemi, A.L.; Umar, M.; Oguche, F.; Aliyu, S.U.; Oyeyemi, A.Y. Accelerometer-determined physical activity and its comparison with the international physical activity questionnaire in a sample of Nigerian adults. PLOS ONE 2014, 9, e87233. [CrossRef]

26. Folstein, M.F.; Folstein, S.E.; McHugh, P.R. "Mini-mental state": A practical method for grading the cognitive state of patients for the clinician. J. Psychiatr. Res. 1975, 12, 189-198. [CrossRef]

27. Chung, M.J.; Wang, M.J. The change of gait parameters during walking at different percentage of preferred walking speed for healthy adults aged 20-60 years. Gait Posture 2010, 31, 131-135. [CrossRef]

28. Aartolahti, E.; Lönnroos, E.; Hartikainen, S.; Häkkinen, A. Long-term strength and balance training in prevention of decline in muscle strength and mobility in older adults. Aging Clin. Exp. Res. 2020, 32, 59-66. [CrossRef]

29. Hughes-Oliver, C.N.; Srinivasan, D.; Schmitt, D.; Queen, R.M. Gender and limb differences in temporal gait parameters and gait variability in ankle osteoarthritis. Gait Posture 2018, 65, 228-233. [CrossRef]

30. Herssens, N.; Verbecque, E.; Hallemans, A.; Vereeck, L.; Van Rompaey, V.; Saeys, W. Do spatiotemporal parameters and gait variability differ across the lifespan of healthy adults? A systematic review. Gait Posture 2018, 64, 181-190. [CrossRef]

31. Almarwani, M.; VanSwearingen, J.M.; Perera, S.; Sparto, P.J.; Brach, J.S. Challenging the motor control of walking: Gait variability during slower and faster pace walking conditions in younger and older adults. Arch. Gerontol. Geriatr. 2016, 66, 54-61. [CrossRef]

32. Cooper, R.; Hardy, R.; Sayer, A.A.; Ben-Shlomo, Y.; Birnie, K.; Cooper, C.; Craig, L.; Deary, I.J.; Demakakos, P.; Gallacher, J.; et al. Age and gender differences in physical capability levels from mid-life onwards: The harmonisation and meta-analysis of data from eight UK cohort studies. PLoS ONE 2011, 6, e27899. [CrossRef]

33. Wheaton, F.V.; Crimmins, E.M. Female disability disadvantage: A global perspective on sex differences in physical function and disability. Ageing Soc. 2016, 36, 1136-1156. [CrossRef] [PubMed]

34. Data and Statistics. Available online: http://www.cdc.gov/physicalactivity/data (accessed on 27 April 2020).

35. Nasirzade, A.; Sadeghi, H.; Mokhtarinia, H.R.; Rahimi, A. A review of selected factors affecting gait symmetry. Phys. Treat. Specific Phys. Ther. J. 2017, 7, 3-12. [CrossRef]

36. Hunter, S.K. Sex differences in human fatigability: Mechanisms and insight to physiological responses. Acta Physiol. 2014, 210, 768-789. [CrossRef]

37. Staron, R.S.; Hagerman, F.C.; Hikida, R.S.; Murray, T.F.; Hostler, D.P.; Crill, M.T.; Ragg, K.E.; Toma, K. Fiber type composition of the vastus lateralis muscle of young men and women. J. Histochem. Cytochem. 2000, 48, 623-629. [CrossRef] [PubMed]

38. Liu, D.; Sartor, M.A.; Nader, G.A.; Gutmann, L.; Treutelaar, M.K.; Pistilli, E.E.; IglayReger, H.B.; Burant, C.F.; Hoffman, E.P.; Gordon, P.M. Skeletal muscle gene expression in response to resistance exercise: Sex specific regulation. BMC Genom. 2010, 11, 659. [CrossRef]

39. Maher, A.C.; Fu, M.H.; Isfort, R.J.; Varbanov, A.R.; Qu, X.A.; Tarnopolsky, M.A. Sex differences in global mRNA content of human skeletal muscle. PLoS ONE 2009, 4, e6335. [CrossRef]

40. Pentikäinen, H.; Savonen, K.; Komulainen, P.; Kiviniemi, V.; Paajanen, T.; Kivipelto, M.; Soininen, H.; Rauramaa, R. Muscle strength and cognition in ageing men and women: The DR's EXTRA study. Eur. Geriatr. Med. 2017, 8, 275-277. [CrossRef]

41. Van Dam, R.; Van Ancum, J.M.; Verlaan, S.; Scheerman, K.; Meskers, C.G.; Maier, A.B. Lower cognitive function in older patients with lower muscle strength and muscle mass. Dement. Geriatr. Cogn. Disord. 2018, 45, 243-250. [CrossRef]

42. Callisaya, M.L.; Beare, R.; Phan, T.G.; Blizzard, L.; Thrift, A.G.; Chen, J.; Srikanth, V.K. Brain structural change and gait decline: A longitudinal population-based study. J. Am. Geriatr. Soc. 2013, 61, 1074-1079. [CrossRef] [PubMed]

43. Dietz, V. Proprioception and locomotor disorders. Nat. Rev. Neurosci. 2002, 3, 781-790. [CrossRef] [PubMed]

44. Tucker, M.R.; Olivier, J.; Pagel, A.; Bleuler, H.; Bouri, M.; Lambercy, O.; del R Millán, J.; Riener, R.; Vallery, H.; Gassert, R. Control strategies for active lower extremity prosthetics and orthotics: A review. J. Neuroeng. Rehabil. 2015, 12, 1. [CrossRef] [PubMed]

45. Baudry, S. Aging changes the contribution of spinal and corticospinal pathways to control balance. Exer. Sport Sci. Rev. 2016, 44, 104-109. [CrossRef] 
46. Song, S.; Geyer, H. A neural circuitry that emphasizes spinal feedback generates diverse behaviours of human locomotion. J. Physiol. 2015, 593, 3493-3511. [CrossRef]

47. Grande, G.; Triolo, F.; Nuara, A.; Welmer, A.K.; Fratiglioni, L.; Vetrano, D.L. Measuring gait speed to better identify prodromal dementia. Exp. Gerontol. 2019, 124, 110625. [CrossRef]

48. Díaz, S.; Stephenson, J.B.; Labrador, M.A. Use of Wearable Sensor Technology in Gait, Balance, and Range of Motion Analysis. Appl. Sci. 2020, 10, 234. [CrossRef]

49. Taniguchi, Y.; Yoshida, H.; Fujiwara, Y.; Motohashi, Y.; Shinkai, S. A prospective study of gait performance and subsequent cognitive decline in a general population of older Japanese. J. Gerontol. A Biol. Sci. Med. Sci. 2012, 67, 796-803. [CrossRef]

(C) 2020 by the authors. Licensee MDPI, Basel, Switzerland. This article is an open access article distributed under the terms and conditions of the Creative Commons Attribution (CC BY) license (http://creativecommons.org/licenses/by/4.0/). 